\title{
Periodismo ciudadano, en los límites de la profesión periodística
}

\author{
Santiago MARTínEZ ARIAS \\ Universidad Complutense de Madrid \\ santiagomarias@ccinf.ucm.es
}

Recibido: 16 de julio de 2015

Aceptado: 18 de septiembre de 2015

\begin{abstract}
Resumen
El periodismo ciudadano se ha convertido en una preocupación para los profesionales, para las empresas periodísticas y para los teóricos de la comunicación que tratan de descifrar las claves de esta, al fin y al cabo, nueva forma de comunicación. Entre los textos dedicados a ello echamos en falta una categorización clara de esta forma comunicativa, y en el contexto de estas investigaciones hemos puesto aquí negro sobre blanco respecto a conceptos sobre los que estamos todos los días discutiendo en redacciones, en las aulas y en la propia red que lo genera. Es urgente un repaso a la cuestión en todos sus términos y elementos, desde su nacimiento hasta la situación actual, para que definitivamente podamos construir una teoría válida para esta comunicación tan actual y tan generalizada.

Palabras clave: Periodismo ciudadano, blog periodístico, periodismo digital, tendencias en periodismo, redes sociales.
\end{abstract}

\section{Citizen journalism, limits of the journalism work}

\begin{abstract}
Citizen journalism has become a concern for journalists, media industry and for communication theorists trying to decipher the apparently secret keys of this new way of communication. Among all the related texts, we miss a clear categorization of this communicative way. In this research environment we provided here some light regarding concepts on which we are daily talking about in newsrooms, classrooms and lectures, and in the own network that generates the citizen journalism. We find necessary to review this issue in all its terms and components, its actual sense, from birth to today's situation, in order to definitely build a valid theory for this so modern and so widespread communication.

Keywords: Citizen journalism, j-blogs, Digital Journalism, Journalism Professional Trends, Social Networks.

\section{Referencia normalizada}

MARTÍNEZ ARIAS, Santiago (2015): "Periodismo ciudadano, en los límites de la profesión periodística". Estudios sobre el Mensaje Periodístico. Núm. especial diciembre, págs.: 109-118. Madrid, Servicio de Publicaciones de la Universidad Complutense.
\end{abstract}

Sumario: 1. Introducción. 2. Estado de la cuestión; 2.1. Teorías; 2.2. Blogs frente a redes. 3. Argumentos a favor y en contra; 3.1. A favor; 3.2. En contra. 4. Conclusiones. 5. Referencias bibliográficas.

\section{Introducción}

Decía Borges que ser periodista era un destino romántico, y añadía por boca de uno de sus personajes de cuento: "No me abochorna haber querido ser periodista, rutina que ahora me parece trivial. Recuerdo haberle oído decir a Fernández Irala, mi colega, que el periodista escribe para el olvido y que su anhelo era escribir para la memoria y el tiempo"1. Estaba reflejando un tiempo y un lugar distintos. Ahora el lugar es la sociedad de la información globalizada, y el tiempo parece inaprehensible, como en

1 BORGES, Jorge Luis (1977) "El Congreso", en El libro de arena, Madrid, Alianza Editorial. 
el borgiano "libro de arena". En este tiempo, el cuasi ahora, Dan Gillmor abandonó en 2005 el San Jose Mercury News para crear el primer blog de un medio de comunicación dando carta de naturaleza al periodismo participativo, y abrió la brecha del conocido como periodismo ciudadano. Sin embargo el fondo es otro, y a pesar de que conocemos la interactividad de los nuevos medios, seguimos preguntándonos si realmente la respuesta o participación del público es periodismo o hay que catalogarlo de otra forma.

No es ningún secreto que los hábitos de consumo de información han cambiado radicalmente en los últimos años. El target de las cabeceras en la red es el público joven, inquieto y culto (Meso, 2005: 5) pero que, además, quiere participar en la realización de los contenidos. Existen millones de páginas informativas, que no periodísticas, y los periodistas profesionales sólo hacen una pequeña parte de esos contenidos. ¿Quién los escribe? La sociedad de la información está en otras manos, ya que no es dominio exclusivo de las empresas. Las empresas informativas están en crisis y buscan fórmulas para salir de ella y una de sus estrategias implica el involucrar a los lectores como parte del proceso informativo (Carrasco, 2010: 72). Los weblogs han facilitado y democratizado la producción de la información. El incorporar al lector a la producción, o mejor dicho a una parte de la producción, no es un fenómeno nuevo. Han sido numerosas las iniciativas mediáticas tradicionales en las que se buscaba la participación ciudadana en la creación, con paneles de lectores o programas audiovisuales llevados por el público. La novedad actual reside en la superación de antiguas barreras tecnológicas gracias a la llegada de Internet (López, 2007: 115).

\section{Estado de la cuestión}

Que el periodismo ciudadano existe es incontestable, aunque haya voces en contra. $\mathrm{Si}$ nos apoyamos en la argumentación teórica, cuando nos dice que el periodismo se verifica cuando el envío del mensaje sea susceptible de ser puesto a disposición de un colectivo significativamente amplio de personas, entonces podemos decir que ese tipo de periodismo existe. Con Internet cualquier ser humano puede ser considerado un comunicador social. Pero debemos ser conscientes de que esto no le convierte en periodista ni lo que hace en periodismo (Real et al., 2007: 191). La pregunta pertinente sería ¿qué uso hacen los ciudadanos de ese periodismo?

Todas estas prácticas en la red pueden ser consideradas como reflejo de nuevos medios pero con características distintas de los tradicionales. En el periodismo en general se ha pasado del monólogo al diálogo y la colaboración como característica principal. Aunque, como señalan otros autores, lo fundamental es tener los filtros adecuados para poder separar lo importante de lo irrelevante (Espiritusanto, 2014: 62). Desde el simple "me gusta" de las redes sociales (como la forma más sencilla de participación, a la que desde luego no se puede llamar periodismo) hasta cualquier otro blog complejo y exhaustivo. También existe otro tipo de participación más activa. Por ejemplo, cuando el ciudadano se encuentra en el momento y el sitio adecuado y se convierte en testigo directo de un acontecimiento, consideramos que está realizando la labor de un periodista. Entonces el ciudadano se convierte en fuente (Espiritusanto, 2014: 65), pero no en periodista. 
Estamos ante un nuevo paradigma comunicacional que ha planteado la necesidad de nuevas definiciones dentro del marco del periodismo. Algunos teóricos creen que tan sólo es una nueva forma de ejercer la vieja, o no tan vieja, profesión. Lo que es indudable es que la incidencia de las tecnologías ha generado una evolución impensable hace unos años y ha trasladado la potencia y capacidad de la profesión periodística al propio público receptor, ahora también emisor de información. Se favorece la participación de la audiencia, y esa participación se ha convertido en la creación del denominado periodismo ciudadano.

La literatura académica al respecto es amplia y en nuestra investigación están resumidos buena parte de esos estudios. En concreto son de inapelable referencia las obras de Mariano Cebrián y Jesús Flores, entre las que destaca Blogs y periodismo en la red (libro de actas del Primer Congreso Internacional de Blogs y Periodismo en la Red, 2006) y que supuso la mayor recopilación en castellano sobre el tema. O la también obra de inexcusable consulta de David Parra y José Álvarez Marcos sobre Ciberperiodismo en el que se ocupan los autores de la modificación de la tradicional estructura de la información debida al nacimiento de este fenómeno.

\subsection{Teorías}

El periodismo ciudadano puede generar un contenido en un medio de Internet en igualdad de condiciones técnicas que el periodismo tradicional. Hay que tener en cuenta que la empresa periodística se basaba antes en la escasez y el control de la información, generando una información de una única dirección. El periodismo ciudadano o participativo ha roto la hegemonía técnica y económica de las empresas informativas.

Para definir este periodismo la fórmula o expresión más extendida es la de periodismo ciudadano. Aunque comprobados los matices de la actividad caben muchas otras fórmulas y a lo largo de los últimos años, la evolución de la propia red ha hecho que se generaran otro tipo de denominaciones. Así tenemos periodismo público, periodismo democrático, periodismo de guerrilla, periodismo de calle, periodismo abierto, periodismo voluntario, e incluso periodismo 3.0 (Espiritusanto, 2014: 64).

Periodismo ciudadano es aquel que hace posible la participación activa de los actores sociales que intervienen en todo el procesamiento de la información de interés público (Meso, 2005: 7). Nace alrededor del año 90 en EEUU y pasa a América Latina y Europa. Sólo en ocasiones tienen el valor de la noticia, ya que profesionalmente hay que filtrar, editar y comprobar la veracidad de los hechos que se publican. Cualquier persona no actúa ni se convierte en periodista por relatar una experiencia sobre un acontecimiento. Así, el movimiento denominado periodismo ciudadano parte de este planteamiento, erróneo para muchos, y el "empecinamiento que desgraciadamente persiste en definir al periodista por la mera actividad ayuda a que el error crezca en magnitud y se generalice hasta límites insospechados" (Real et al., 2007: 190).

Un matiz fundamental es el ofrecido por Frank La Rue quien señalaba que existe una especial categoría de periodistas ciudadanos en las personas que juegan un papel activo en determinados acontecimientos sociales, y que trabajan como un periodista destacado ante un acontecimiento, con el consiguiente riesgo personal y que realiza 
tareas periodísticas en el más estricto sentido de la palabra² ${ }^{2}$. Son esos informadores vocacionales los que han demostrado su valor periodístico informando en situaciones especialmente dramáticas y, como decimos, con riesgo para su integridad personal.

$\mathrm{Al}$ igual que las empresas periodísticas "arman" a sus reporteros con un aparato tecnológico suficiente para hacer frente a la cobertura de diversos acontecimientos informativos, los periodistas ciudadanos disponen en ocasiones de las mismas herramientas. Todo ello ha facilitado aparentemente la labor de los periodistas y ha puesto al mismo nivel tecnológico a los ciudadanos.

Otro aspecto distinto es que en el plano teórico hay que referirse necesariamente a las definiciones o planteamientos de Dan Gillmore, Jay Rose o Howard Rheingold, como pioneros de la materia. Se señala al periodismo cívico como antecedente del periodismo participativo en la red (García de Madariaga, 2006: 215). Es un nuevo paso dado a partir del "Nuevo Periodismo", acuñado a lo largo de la segunda mitad del siglo XX como reflejo del periodista vigilante y protector de la democracia, el gatekeeper, pasando a convertirse más tarde en el mukraker o "escarbador de basura" que denunciaba los abusos de poder. Esa evolución creció exponencialmente con la aparición de Internet a finales del siglo XX. Las nuevas tecnologías dieron paso a la evolución de los medios -formatos y géneros implicados- y abrieron los medios a la participación directa en la generación de informaciones.

La clasificación resulta compleja a pesar de todo. Hablamos de periodismo cívico, periodismo de participación, periodismo ciudadano, y otras clasificaciones que surgen puntualmente como por ejemplo los "ninjas" en Brasil. Éstos últimos son los denominados Midia Ninjas, creados por jóvenes activistas que se definen como narrativas independientes, periodismo y acción (Narratives Independents, Journalism and Action). Nacieron con las manifestaciones de Brasil en junio de 2013, contra la corrupción política y el Campeonato Mundial de Fútbol. Estos informadores contaban lo que los medios no transmitían, con cargas policiales y enfrentamientos violentos durante las protestas. AFP, la prensa oficial tradicional en su web, lo ilustró con un vídeo sobre su ascenso ${ }^{3}$. De esta forma, con un teléfono móvil en una mano, y en la otra una botella de agua, se puede hacer información ciudadana. Se publica en tiempo real, como cualquier otro ciudadano, pero sin editar y sin cortar.

\subsection{Blogs frente a redes}

Cuando nos preguntamos dónde puede convertirse el ciudadano en periodista tenemos diversos espacios que analizar. Desde los comentarios o contribuciones a los medios tradicionales en Internet, sean escritos o audiovisuales, multimedia en cualquier caso, o en la creación de sus propios "medios". Y ello se da técnicamente en la puesta en marcha de los blogs periodísticos. No sólo en el desarrollo comercial de las grandes empresas de Internet, sino en los propios cuadernos de bitácora ciudadanos especializados. De ahí precisamente la importancia cada día más evidente del periodismo es-

2 65 Sesión de Asamblea General de la ONU, en Espiritusanto, 2014: 59.

3 AFP: https://www.youtube.com/watch?v=JHIm8HJPpNs\&feature=youtu.be. 
pecializado. El blog es fórmula popular de expresión y comunicación social (García de Madariaga, 2006: 210).

Cuando hablamos de blogs en este contexto nos estamos refiriendo a blogs periodísticos. Es decir, no todos los blogs tienen que ver con el periodismo, ni siquiera una pequeña parte, pero nosotros nos referiremos a aquellos como un nuevo formato periodístico facilitado por el hecho de la rápida evolución de las nuevas tecnologías. Los blogs periodísticos poseen una carga de opinión por encima de la informativa ya que las informaciones principales suelen estar tomadas de otros medios profesionales. $\mathrm{La}$ facilidad del recurso de la red da la posibilidad de escribir sobre un tema, pero la falta de otro tipo de recursos impide hacer una labor periodística en profundidad. Aunque el ciudadano tiene ahora la misma capacidad de difundir a través de Internet información, no tiene la capacidad y los recursos de un medio tradicional para acceder a determinada información y poder contrastar (Real et al., 2007: 190).

Tendremos que tener en cuenta cómo, además, las propias empresas informativas saben que éste es un potente medio de manera que, con diversas fórmulas, hacen que sus profesionales desde dentro de las empresas, columnistas principalmente, tengan su bitácora personal dentro de los propios medios, aunque gestionados con recursos humanos y profesionales de la empresa. En cierto momento las empresas ponían recursos tecnológicos y humanos a disposición de estos profesionales para gestionar este tipo de redacciones extra-periodísticas. Esta práctica empezó a realizarse en grandes diarios norteamericanos, con grandes firmas, y ya se ha trasladado a Europa.

De los 29.000 blogs activos en el año 2000 se pasó en cinco años a los 60 millones. Así se incorporaron a lo que se denominó j-blogs. Es decir blogs no amateurs, sino profesionales de los medios con su propio espacio, tanto fuera como dentro de las empresas informativas. Se trata, además, de buscar una mayor libertad en la comunicación de contenidos con el objetivo de "potenciar una forma de comunicación lo menos mediada posible, interactiva, comunitaria y transversal, mediante la construcción colectiva y permanente de la noticia" (García de Madariaga 2006: 211). El fenómeno participativo se multiplicó por tanto con la llegada de los weblog, con proyectos de comunicación personal de muy diverso contenido. De la mano de los avances de la tecnología, especialmente de los lenguajes de programación, estas herramientas llegaron a la mayoría de los cibernautas que, sin tener muchos conocimientos tecnológicos, descubrieron la facilidad para crear su publicación personal (López, 2007: 112).

De esta forma aparece el ciudadano como generador de contenidos, más o menos elaborados -normalmente menos-, y el desarrollo comercial de diversos ámbitos de las empresas implicadas en la red. Otro factor o aspecto a tener en cuenta es cómo los propios profesionales se sumaron a la corriente. Se trata en este caso de los blogs, como fórmula popular de expresión y comunicación social. "Durante la invasión de Irak, muchos corresponsables de guerra compaginaron su labor profesional con el mantenimiento diario de sus blogs personales, en los que presentaban versiones más heterodoxas de sus crónicas y reportajes" (García de Madariaga 2006: 207). Y así como algunas cadenas censuraban a sus reporteros, caso de CNN con Kevin Sites, otras como la BBC aprovecharon el "tirón informativo" ofreciendo recursos a sus periodistas. 


\section{Argumentos a favor y en contra}

En general encontramos voces en ambos sentidos. Si bien están mezcladas unas y otras, podemos decir que las académicas están más a favor y las profesionales más en contra. Espiritusanto nos habla del nuevo "ecosistema" comunicacional, como el que hemos descrito arriba, y de la mala interpretación que se hace del papel del periodismo ciudadano dentro de él. Las razones por las que los usuarios deciden comenzar a crear sus medios ciudadanos son diversas, pero la principal es la pérdida de credibilidad del periodismo tradicional, incluso en su nueva vertiente cibernética. Los ciudadanos crean un punto de vista sencillo y más crítico en general al no depender de la remuneración económica.

Este es un debate tradicional que a priori no tiene que ver con los nuevos medios, sino con el desarrollo económico de las empresas informativas y de la sociedad en general. Sin embargo, la posibilidad de tener voz, en una aparente igualdad de condiciones tecnológicas por parte del ciudadano de a pie, ha provocado que esa barrera sea rota y que esas personas puedan ser escuchadas y aun seguidas.

\subsection{A favor}

Tenemos a los usuarios en igualdad de condiciones técnicas (Espiritusanto, 2014: $60)$ y ello genera de alguna forma una serie de beneficios inherentes a esa participación de los usuarios en los nuevos medios. Hay que reconocer que la incorporación del ciudadano a la provisión de contenidos es necesaria. Según los teóricos del periodismo participativo así es. Siempre desde la perspectiva de la colaboración y no de la intrusión. Gillmore, Bowman o Willis presentan las ventajas de incorporar a los ciudadanos ${ }^{4}$.

Los ejemplos son diversos, desde la experiencia de la colaboración en un artículo de la famosa revista Jane's Intelligence Review sobre ciberterrorismo a otras de similar calado en el denominado "periodismo de fuente abierta" (en alusión a los códigos de fuente abierta, o distribución gratuita de software, como el sistema operativo de Linux o todas las aplicaciones con él relacionadas). Es particularmente paradigmático el caso de la revista coreana OhMyNews!, medio participativo, con una red de corresponsales ciudadanos de más de 40.000 miembros en todo el mundo, que lo convierte además en el medio más seguido de Corea del Sur ${ }^{5}$. En España se han producido aproximaciones a este fenómeno en diario de formato más popular, que se

4 Bowman, Shayne y Willis, Chris 2003 "We Media", The Media Center at the American Press Institute http://www.hypergene.net/wemedia 2004 (consultado noviembre 2013).

$5 \mathrm{Oh}, \mathrm{MyNews}$, pionero en esta iniciativa, que sólo demandaba a sus nuevos reporteros un buen dominio del inglés y sus datos personales. Estos son todos los requisitos previos necesarios para comenzar a trabajar como periodista. Incluso reciben una pequeña gratificación económica por sus esfuerzos y desvelos en la caza de noticias. Estos peculiares colaboradores aportan un 70\% del contenido del periódico. (Real et al., 2007: 191). En la actualidad Ohmynews existe bajo la marca International Oh My News. Los artículos pertenecientes a la pasada etapa siguen existiendo en forma de Archivo bajo la marca ohmynews.com. 
acercan más a la agenda local, como Qué!, 20 minutos, Gennio calle o Reportero Digital. En este sentido aparece también el concepto de curaduría en el periodismo ${ }^{6}$.

También los grandes medios internacionales se han convencido de la necesidad de la creación de espacios participativos en sus propias web como por ejemplo BBC o CNN, quien presentaba en 2006 una plataforma de publicación ciudadana de información, aunque con la observación de diversos filtros por parte de la empresa antes de su publicación general. En España la publicación gratuita Qué! presentó el "primer diario español elaborado por sus propios lectores" (Meso, 2005: 10) cubriendo así una demanda informativa no satisfecha por los medios. Manuel López lo define como "un tratamiento de la información basado en la complicidad y corresponsabilidad del medio con los problemas de una colectividad concreta" (Meso, 2005: 12).

Bowman y Willis hablan del "diario nuestro", que incluso utilizan como título de su texto, para definir este tipo de medios. Señalan que los medios que consigan adaptarse al periodismo ciudadano podrán destacar en el espacio informativo global. Habrán de responsabilizar a sus redacciones en el cambio y en la nueva organización para lograr un medio más eficiente y cercano a los lectores (Carrasco, 2010: 73).

\subsection{En contra}

Los profesionales son los que cierran filas para defender la posición contraria al periodismo ciudadano. En Análisis del periodismo ciudadano Ron Steinman se descubre como "un detractor del modelo de periodismo ciudadano tan de moda en la actualidad, sus opiniones sobre la actualidad y el futuro de los medios de información tienen mucho que ver con la mayoría de las opiniones de periodistas y analistas que estudian la situación" (Carrasco, 2010: 73). En este estado de cosas se acusa también al periodismo ciudadano de la falta de credibilidad del periodismo en general. Aunque otros ponen el acento en el fracaso de la gestión empresarial de los medios de comunicación tradicionales y su incapacidad de adaptación a los nuevos medios. Los medios tradicionales cargan contra ellos al no considerarlos periodismo, sin embargo nos debemos preguntar si ¿existe un único tipo de periodismo? Los medios técnicos en manos de los usuarios están cambiando ese panorama.

Históricamente la enseñanza del periodismo llega a la sociedad mucho después que la profesión periodística, oficio para algunos en el debate clásico. Lo que se enseña en las aulas es el criterio periodístico basado en dos pilares fundamentales: el rigor ético que debe acompañar al profesional y la formación técnica, imprescindible para el ejercicio periodístico (Sánchez, 2014). Este es uno de los argumentos del profesor Sánchez cuando narra cómo un hecho falso sobre un presunto sabotaje en el Metro de Madrid, transmitido a través de las redes por el periodismo ciudadano, se convirtió en noticia incluso para los medios profesionales. El periodismo ciudadano no tiene la venia profesional, y su valor reside en otro tipo de virtud (López, 2007).

6 Actualmente se manejan dos conceptos que son muy distintos: "Content curation" (curaduría de contenidos) para la selección, organización, puesta en valor y difusión de contenidos digitales sobre un determinado tema; y "Digital curation" (curaduría digital) para la conservación de la información guardada digitalmente, que enfrenta serias amenazas de desaparición por la rápida obsolescencia de los formatos digitales (Tortolini, 2013). 
Se hablaba de intrusismo cuando en los medios de comunicación existían oficiantes que ejercían la profesión sin aquella "bendición académica" que otorgan las aulas, y ello es trasladable sin duda al quehacer del llamado periodismo ciudadano. El necesario paso por las aulas ofrece el rigor ético con el que un profesional de la información debe desempeñar su función social. Función de mediador cultural y social básica en la actividad informativa y cuya correcta técnica es imprescindible para el buen desempeño profesional. Así, en las facultades de comunicación se inicia a los futuros graduados en una amplia panoplia de medios (prensa escrita, audiovisual e Internet). Y es ahí donde choca con la tecnología al alcance de todos. Todo lo cual supone un ejercicio de calidad a la hora de transmitir la información al ciudadano (Sánchez, 2014).

En las aulas se aprenden códigos, se enseñan géneros, se muestran técnicas y distintos tipos de medios, y esa es la perspectiva que le faltará al "intruso". De ahí la necesaria colaboración antes señalada y la puesta en marcha de iniciativas de enseñanza extra académica del periodismo, el periodismo de calidad. Existen muchas iniciativas universitarias de medios para alumnos de esta disciplina que, lejos de ser un medio profesional en sentido estricto - ya que la persona que realiza su contribución no obtiene unos emolumentos por el desarrollo de esa labor- sirven para mostrar al alumno y poner en práctica sus habilidades. Un banco de pruebas, laboratorio periodístico, inmejorable para practicar esas capacidades vocacionales o no. Se trata más de un compromiso adquirido con la sociedad a través de las universidades que garantiza la labor del periodismo.

La teoría indica cómo el profesional de la información periodística no se caracteriza por captar sin más los hechos. Hay que buscar el significado que esos hechos poseen, de forma que la objetividad y la veracidad del periodista en esta ocupación son elementos esenciales e imprescindibles. Así el periodista profesional debe saber ponderar los diferentes pareceres con justicia, sin razonamientos personalizados que no tengan su base en los datos y los hechos acontecidos. (Real et al., 2007: 196).

En ese sentido se orienta la argumentación de Steinmann ${ }^{7}$ en la entrevista realizada por la versión digital de $\mathrm{ABC}$ a raíz del artículo publicado por el periodista y titulado El periodismo ciudadano: una receta para el desastre. Steinmann está en contra de este tipo de periodismo porque, en primer lugar, los medios utilizan a los ciudadanos como periodistas en momentos de crisis, y ante determinadas faltas de cobertura, y no porque aporten algo positivo a la calidad de los medios. Otra razón es la falta de calidad del trabajo realizado debido a la falta de experiencia y de entrenamiento del ciudadano en las labores periodísticas, que además no quiere ser corregido (Carrasco, 2010: 72).

7 Steinman es actualmente editor ejecutivo de The Digital Journalist. En este medio analiza y compara el trabajo del periodismo actual, muy centrado en La Red y en las Nuevas Tecnologías con el que ha ejercido durante muchos años, más de treinta y cinco, en el ámbito de los medios tradicionales (Carrasco, 2010: 73). 


\section{Conclusiones}

En una obra que ha cobrado inusitada actualidad en el momento de escribir este texto (primavera de 2014) contaba el autor teatral Albert Boadella cómo a la hora del desayuno compartía con su mujer Dolors las noticias del día. Refiriéndose a ese momento señalaba: “...hay que saber extraer la sustancia de cada cosa, detectando los niveles de falsedad, ignorancia y tergiversación de los medios (que son hoy considerables)" Hoy como bien lo expresa un adagio nacional, valga el término, "hay que saber separar el grano de la paja". En el contexto del periodismo ciudadano parece sencillo. Si atendemos a los profesionales, contra, está claro, y si atendemos a los académicos, pro, también. Sin embargo, como dice Boadella "hay que extraer la sustancia de ambos". Porque, seamos realistas, todo periodismo tiene sus virtudes y sus defectos, tanto a un lado como a otro de la trinchera profesional. El problema en este caso del periodismo ciudadano es saber dónde está el interés ya que nos encontramos ante distintos niveles informativos, del general al hiperlocal.

Podemos establecer varios niveles de información, a saber: información confidencial, información de los medios tradicionales, información ampliada de los medios tradicionales en Internet, información periodística a través de redes sociales, e información personal (con dos subniveles a su vez, información de agenda -interesante periodísticamente- e información personal para uso restringido -dependiendo del nivel de acceso en las redes sociales- que también conforma el periodismo ciudadano).

Se nos plantean varios problemas. El primero es el nivel de acceso a la información y el segundo el del nivel de interés de la información sea general o sea particular. El valor del periodismo ciudadano parece evidente, sin embargo hay que distinguir en esos niveles de acceso y de distribución de información dónde se pueden y se deben poner los límites a una u otra forma de intercambio de la información.

Sin duda el universo del periodismo ciudadano, a pesar de las voces en contra, se ha manifestado como un tipo de periodismo o de distribución de información distinto con un enorme potencial en la sociedad actual.

\section{Referencias bibliográficas}

BOADELLA, Albert (2007): Adiós Cataluña. Madrid, Espasa.

BORGES, Jorge Luis (1977): El libro de arena. Madrid, Alianza Editorial.

BOWMAN, Shayne and WILLIS, Chris (2003): "We Media", The Media Center at the American Press Institute http://www.hypergene.net/wemedia 2004 [Consulta: noviembre 2013].

CEBRIAN Herreros, Mariano y FLORES Vivar, Jesús (Editores, 2007): Blogs y periodismo en la red. Madrid, Fragua.

ESPIRITUSANTO, Óscar (2014): "Periodismo ciudadano: colaboración y evolución positiva", en "Informe sobre la transformación de los medios de comunicación". Cuadernos de Periodistas, $\mathrm{n}^{\mathrm{o}} 27$, pp. 57-65.

${ }^{8}$ BOADELLA, Albert (2007) Adiós Cataluña, Madrid: Espasa. 
GARCÍA DE MADARIAGA, José María (2006): "Del periodismo cívico al participativo: nuevos medios, viejas inquietudes". Zer n ${ }^{\circ} 21$, pp. 203-217.

LÓPEZ GARCÍA, Xosé (2007): "Gestión de las vías de participación en el ciberperiodismo", en Estudios sobre el Mensaje Periodístico, vol. 13, pp. 111-121. Madrid, Servicio de Publicaciones de la Universidad Complutense.

MESO AYERDI, Koldobika (2005): "Periodismo ciudadano: voces paralelas a la profesión periodística". Revista Latinoamericana de Comunicación Chasqui $\mathrm{n}^{\circ}$ 90, junio, pp. 4-15.

PARRA VALCARCEL, David y ALVAREZ MARCOS, José (2004): Ciberperiodismo. Madrid, Síntesis.

REAL, Elena; AGUDIEZ, Pinar; y PRÍNCIPE, Sergio (2007): "Periodismo ciudadano versus periodismo profesional: ¿somos todos periodistas?". Estudios sobre el Mensaje Periodístico, vol. 13, pp. 189-212. Madrid, Servicio de Publicaciones de la Universidad Complutense.

SÁNCHEZ, Gabriel (2014): "El valor de la información verdadera", en "Informe sobre la transformación de los medios de comunicación", Cuadernos de Periodistas, $\mathrm{n}^{\mathrm{o}} 27$, pp. 66-71.

TORTOLINI, Alejandro Orbisdigitalis (Blog): http://orbisdigitalis.wordpress.com. [Consulta: 10 de noviembre de 2013]. 